\title{
Design and Testing of Fuzzy Logic Based Controller for Active Suspension System of a Quarter Car Model
}

\author{
N. Vivekanandan, A. M. Fulambarkar
}

\begin{abstract}
In today's scenario, due to increase in sales of Sports Utility Vehicles (SUV's) more and more people are opting for off road drive. The main challenge is to improve the performance based on handling and comfort. Hence the conventional static spring and damper system are being modified to accommodate semi-active and active systems. In this paper to study the effectiveness of active suspension system, a quarter car model is developed and Fuzzy control strategy is proposed to reduce displacement of chassis. Hydraulic actuator is used to provide active control in the suspension system of the quarter car model. The fuzzy logic controller is interfaced with the hardware system by LabVIEW software. For connecting the hardware with LabVIEW software Arduino is used. The comparison of active and passive suspension system shows that the chassis displacement is decreased by $30 \%$ in case of active suspension system whereas the settling time decreases by $69 \%$.
\end{abstract}

Keywords: Active suspension; Fuzzy control, Quarter Car, Hydraulic Actuator.

\section{INTRODUCTION}

In recent years of post-liberalization, the Indian roads seem to be flooded with a greater number of international cars. The car makers of all around the world are keen to enter the Indian market because of the increasing car market in India. Before liberalization the Indian car industry was not offering any special safety features to Indian customers though these were compulsory in countries like the U.S.A, U.K, etc. But soon after the liberalization as the world giants of car industries began to Indian market, the Indian consumer is offered with latest luxurious and safety features like active suspension system, seat belts, side-impact bars, air bags, collapsible steering and etc. In order to maintain a good tyre - road contact, the acceleration of the sprung mass has to be reduced

Revised Manuscript Received on February 05, 2020.

* Correspondence Author

Vivekanandan N.*, Mechanical Engg. Dept., Research Scholar, Dr. D. Y. Patil Institute of Tech., \& Asst. Prof., Pimpri Chinchwad College of Engg., Pune, India. Email: n.vivekanandan@pccoepune.org

Dr. A. M. Fulambarkar, Mechanical Engg. Dept., Prof. \& Principal, Pimpri Chinchwad College of Engg., Pune, India. Email: fajay@rediffmail.com

(C) The Authors. Published by Blue Eyes Intelligence Engineering and Sciences Publication (BEIESP). This is an open access article under the CC BY-NC-ND license (http://creativecommons.org/licenses/by-nc-nd/4.0/) and adequate deflection in suspension should be provided. An effective suspension system should reduce the acceleration of sprung mass and provide sufficient deflection to maintain tyre -road contact. Passive suspension system is most common in roads today. For the comfort and safety of the passengers and luggage as well as the sturdiness of the vehicle's components it is necessary to have a well-tuned suspension system. The ultimate function of the suspension system is to improve ride comfort, and this can be attained by reducing forced that is transmitted to the vehicle body from irregularities in the road and to maintain tire-road contact. In design of Active Suspension system road irregularities are linked to excitation of a vehicle. The vehicle movement with constant velocity is the major assumption made. It is possible to improve ride comfort in Active Suspension system without the loss of controllability. In Fuzzy Logic Controller (FLC) is attracting a major interest in the design of Active Suspension control system. The human expertise can be used in Fuzzy logic controller without the need of actual mathematical model. Apart from this FLC can tolerate uncertainties regarding different input parameters and therefore it has inherent robustness. By using the FLC there is a possibility of tuning according to different operating conditions.

\section{LITERATURE REVIEW}

Wei Wang et. al. (2014) have discussed quarter car model for their work in which the control objective was to study vertical vibrations of quarter car model and control the vibrations. Active suspension system is complex in nature so fuzzy logic is used to gain control over the system and fuzzy logic does not require accurate model as that done by mathematical model so to get the membership values and rules, they have used cultural algorithm. Quarter car model is used [1]. Weichao Sun et. al. (2013) have discussed constrained control system for vehicle suspension system. Performance requirement for vehicle active suspension system has been explained. Problem has been formulated by considering quarter car model. Dynamic equations for sprung mass and unsprung mass have been derived after this state space equation is derived to decide the boundary of problem [2]. M. Soleymani et. al. (2012) in their work considered a full vehicle model to carry out experiment. Dependency of development of problem statement on vehicle ride comfort along with the vehicle speed is well explained. 
Eight degrees of freedom has been selected for full vehicle system. Optimization objectives are explained along with the ISO standard 2631 [3]. Wei-Yen Wang et. al. (2012) in his work studied integrated control algorithm which describes of a controller used for both ABS and Active suspension system. It was observed that back stepping control system, sliding mode control system and fuzzy control system assumed that dynamic control system is available [4]. Guido Koch et. al. (2010) in his research designed a quarter car with active suspension. The nonlinear dynamic behavior of suspension system was studied validated experimentally the Active Suspension controller [5]. Jeen Lin et. al. (2009) suggested a Fuzzy Sliding Mode Controller (FSMC) for performing control performance in an active suspension system. They developed a quarter-car hydraulic suspension system for accessing and relating the traditional fuzzy logic controller (TFC) performance with other intelligent controllers [6]. Semiha Turkay et. al. (2007) derived restrictions on transfer functions from the disturbances in the road. These constraints were determined for a spectrum of the suspension parameters [7]. T. Yoshimura et. al. (2000) developed an active suspension system of quarter car model with sliding mode control. The construction of quarter car model with an active suspension system is discussed [8]. Nizar Al-Holou et. al. used an Adaptive Fuzzy Logic-based controller, in integration with feed-forward network for an active suspension system. The AFLC performance is demonstrated in this paper [9]. P. Swethamarai and P. Lakshmi (2019) designed active quarter car mode with Improved driver ride quality. In this paper, MATLAB/Simulink is used to analyze the performance of the controllers. A Fuzzy Tuned PID Controller (FPID) is used to improve ride by reducing the Driver Body Acceleration [10].

\section{ANALYTICAL STUDY}

For doing analytical study before designing the controller and Simulink model a mathematical model is developed for a quarter car model which is described below.

\section{A. Mathematical model for quarter car model}

A 2 degree of freedom "quarter-car" automotive active suspension system is shown in Figure 1. It illustrates the axle motion and vehicle body motion of a wheel. Quarter car model is considered because its simplicity and all the parts of suspension system and tyre along with their deflection are observed.

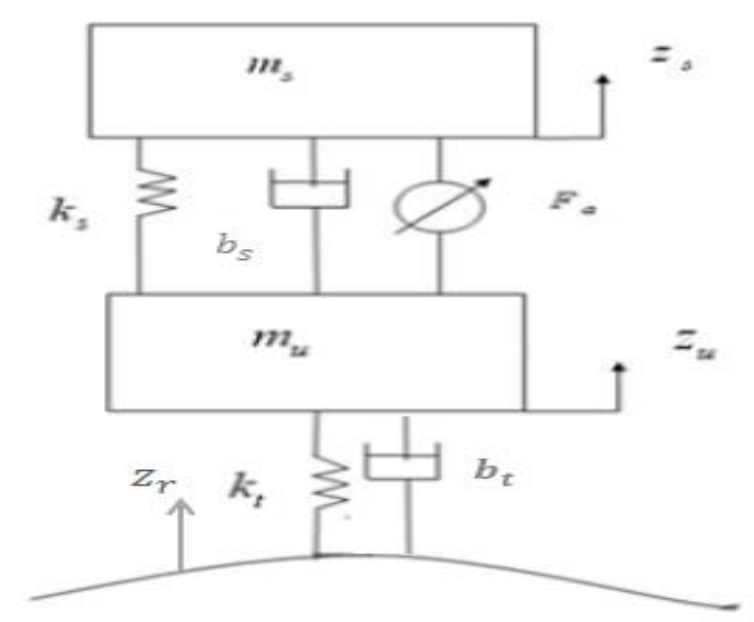

Figure 1. Quarter car model

The system consists of a spring $k_{s}$, a damper $b_{s}$ and an active force actuator $F_{a}$. In passive suspension the active force can be set to zero. The sprung mass $\mathrm{m}_{\mathrm{s}}$ represent the quarter car corresponding to the vehicle body mass. $\mathrm{m}_{\mathrm{u}}$ indicates mass of axle and tyre of an unsprung mass. $\mathrm{k}_{\mathrm{t}}$ represents vertical stiffness of the tyre and $b_{t}$ represents the spring damping. vertical displacements from static equilibrium of the sprung mass, unsprung mass and the road respectively is represented by $z_{s}, z_{u}$ and $z_{r}$ represent the. Equations of motion of the two degree of freedom quarter car suspension is given by

$$
\begin{gathered}
\mathrm{m}_{\mathrm{s}} \mathrm{Z}_{\mathrm{s}}=\mathrm{F}_{\mathrm{a}}-\mathrm{k}_{\mathrm{s}}\left(\mathrm{Z}_{\mathrm{s}}-\mathrm{Z}_{\mathrm{u}}\right)-\mathrm{b}_{\mathrm{s}}\left(\dot{\mathrm{Z}}_{\mathrm{s}}-\dot{\mathrm{Z}}_{\mathrm{u}}\right) \\
\mathrm{m}_{\mathrm{u}} \ddot{\mathrm{Z}}_{\mathrm{u}}=\mathrm{k}_{\mathrm{s}}\left(\mathrm{Z}_{\mathrm{s}}-\mathrm{Z}_{\mathrm{u}}\right)+\mathrm{b}_{\mathrm{s}}\left(\dot{\mathrm{Z}}_{\mathrm{s}}-\dot{\mathrm{Z}}_{\mathrm{u}}\right)+\mathrm{k}_{\mathrm{t}}\left(\mathrm{Z}_{\mathrm{r}}-\mathrm{Z}_{\mathrm{u}}\right)-\mathrm{F}_{\mathrm{a}}
\end{gathered}
$$

The spring and tyre stiffness are assumed to be linear in the range of operation and the tyre is continuously in contact with the ground.

\section{Fuzzy Logic Controller}

The precise mathematical model of the system is not required in knowledge-based control, Fuzzy logic. Generally, the experiences are used to form the control rules for the fuzzy sets. Fuzzy logic theory is a powerful tool and can be used for complex systems. Linguistic variables like small, big, very big represent the domain knowledge, and their membership values lies between 0 and 1 .

\section{B. Fuzzy Logic Controller (FLC) design}

The Mamdani FLC with two inputs namely Suspension Displacement (SD) and Suspension Velocity (SV) are used. $\mathrm{SD}$ is the chasis and wheel relative movement and SV is velocity. The actuator force is the output obtained. 7 Membership Functions (MFs) are NL, NM, NS, Z, PS, PL, and $\mathrm{PB}$ and there are 49 rules in the rule base. It is assumed that all input MFs are identical in shape and triangular MF is used.

\section{Fuzzy Rule Base}

Th fuzzy rule bas is created as shown in Table 1. 
Table 1. Fuzzy rule base

\begin{tabular}{|c|c|c|c|c|c|c|c|}
\hline SD & $\underset{\rightarrow}{\mathrm{NL}}$ & $\mathrm{NM}$ & NS & Z & PS & $\mathrm{PM}$ & $\mathrm{PL}$ \\
\hline NL & PL & PL & $\mathrm{PM}$ & $\mathrm{PM}$ & PS & PS & $\mathrm{Z}$ \\
\hline NM & PL & $\mathrm{PM}$ & $\mathrm{PM}$ & PS & NS & $\mathrm{Z}$ & NS \\
\hline NS & PM & $\mathrm{PM}$ & PS & Z & Z & NS & $\mathrm{NM}$ \\
\hline $\bar{Z}$ & $\mathrm{PM}$ & PS & NS & $\mathrm{Z}$ & $\mathrm{Z}$ & NS & $\mathrm{NM}$ \\
\hline PS & PS & NS & $\mathrm{Z}$ & $\mathrm{Z}$ & NS & NS & $\mathrm{NM}$ \\
\hline $\mathrm{PM}$ & NS & $\mathrm{Z}$ & NS & $\mathrm{Z}$ & NS & NM & NL \\
\hline PL & $\mathrm{Z}$ & NS & NS & NS & NM & NL & NL \\
\hline
\end{tabular}

\section{MATLAB Programming}

Fuzzy logic toolbox from MATLAB is used to design the active suspension system. Mamdani system is used to design rule base. Gaussian membership functions are used to describe input and output parameters.

Figure 2 shows two input functions on left named suspension travel and suspension velocity which are provide as an input to the controller and one output named actuator force on right which is provided by the controller to the actuator in the system. The Figure 3 shows representation of sets for Suspension travel membership function in MATLAB. Triangular functions are used to describe these sets. The horizontal axis represents values for suspension travel and vertical axis represents membership function values. Range for suspension travel is taken from $(-10,10)$ and sets are distributed within this range.

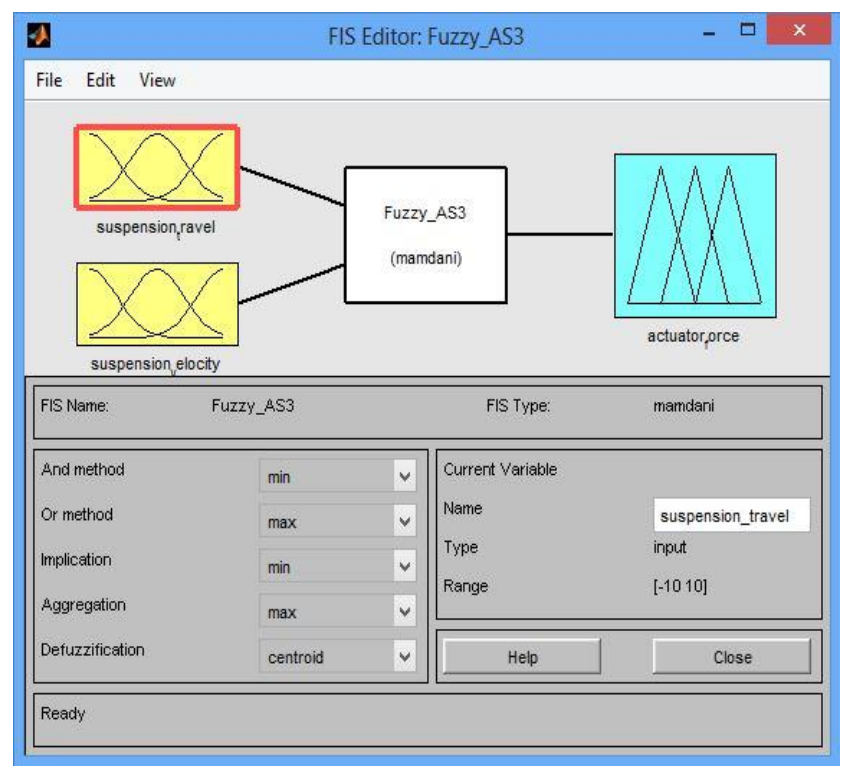

Figure 2. Input and output representation

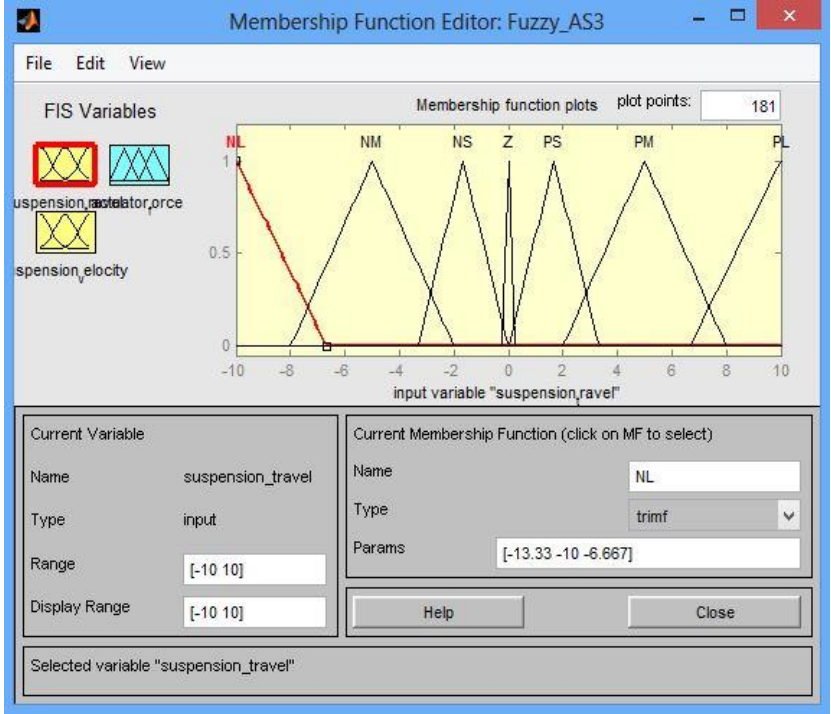

Figure 3. Suspension Displacement Representation

Figure 4 shows representation of sets for Suspension Velocity membership function in MATLAB. Triangular functions are used to describe these sets. The horizontal axis represents values for suspension velocity and vertical axis represents membership function values. Range for suspension velocity is taken from $(-5,5)$ and sets are distributed within this range.

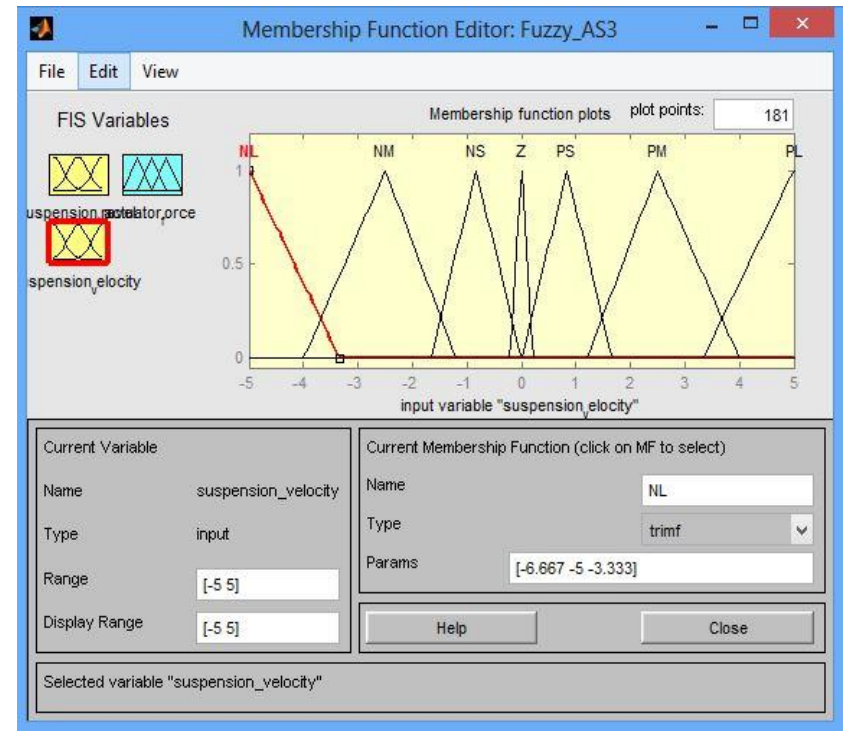

Figure 4. Suspension velocity representation

Figure 5 shows representation of sets for Actuator Force membership function in MATLAB. Triangular functions are used to describe these sets. The horizontal axis represents values for Actuator Force and vertical axis represents membership function values. Range for Actuator Force is taken from $(-2500,2500)$ and sets are distributed within this range. 


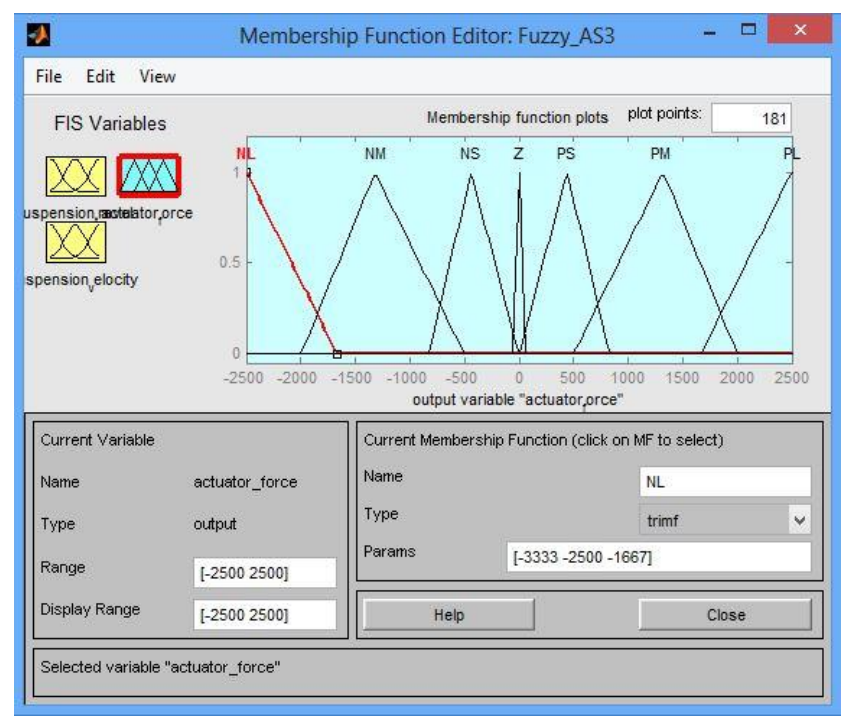

Figure 5. Actuator force representation

Figure 6 shows the representation of fuzzy rules in MATLAB for this fuzzy logic controller. The controller works according to these rules. The rules decide that on when inputs are given what must be the output provided by the fuzzy logic. Rules are provided for two connections (and connection) and (or connection). (And connection) works on maxima principle and (or connection) works on minima principle. After defining suspension travel, suspension velocity, actuator force and rules in MATLAB,

it generates rule viewer shown in Figure 7 from which we can determine the values of actuator force for every value of suspension travel and suspension velocity accordingly.

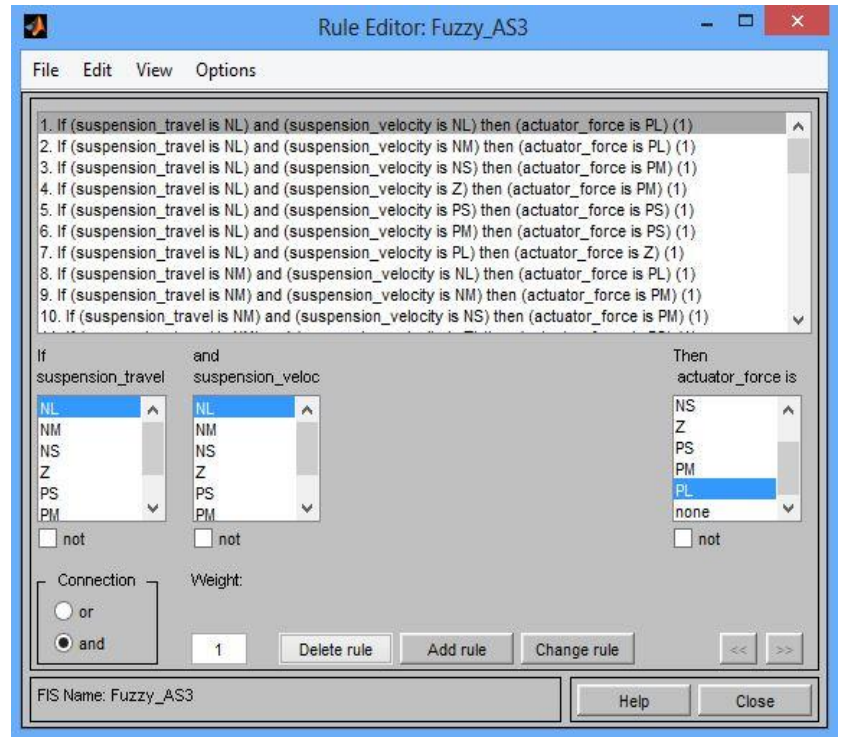

Figure 6. Representations of rules of fuzzy logic controller

The first two columns are for the inputs which are represented by suspension travel and suspension velocity. Varying this input will vary the actuator force in the third Colum. Some cases are explained in next section.

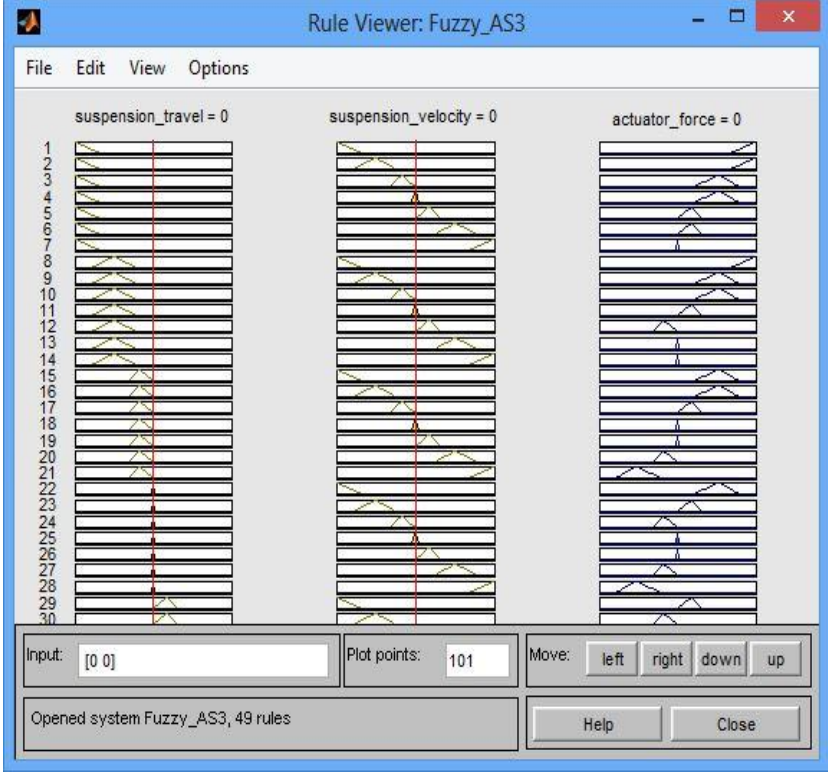

\section{Figure 7. Rule Viewer}

After seeing the rule viewer, we can also see the surface diagram as shown in Figure 8. The surface viewer shows 3 axes on which ' $\mathrm{i} / \mathrm{p}$ ' \& ' $\mathrm{o} / \mathrm{p}$ ' is plotted. The vertical axis represents actuator force. Figure shows actuator force requirement for given case to bring system in stable condition.

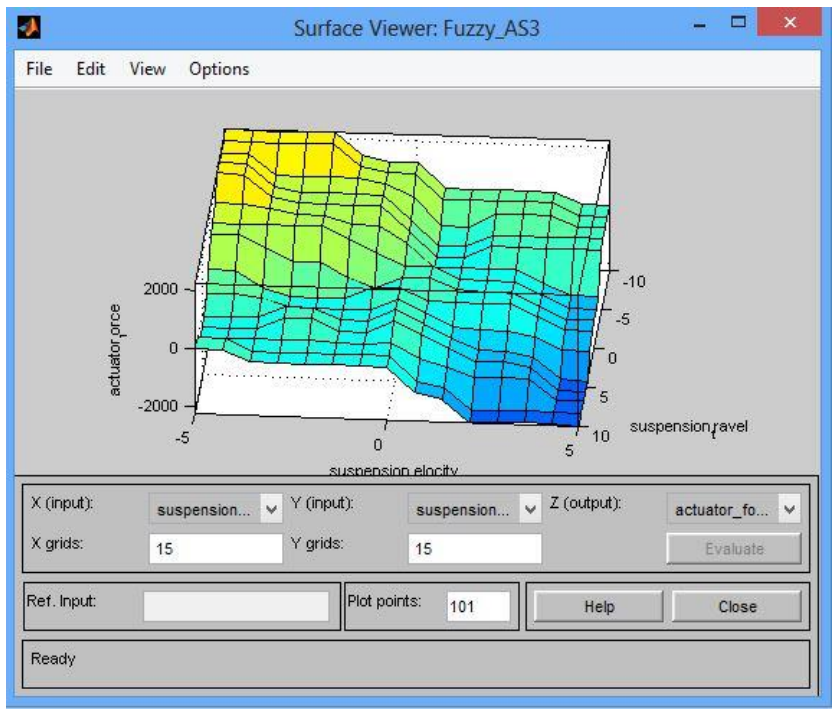

Figure 8. Surface viewer

\section{Cases Discussion}

After defining both input parameters and output parameter along with rules we can calculate easily the actuator force required at different locations. Let us consider following cases:

Case-1

When the inputs are given as Suspension travel (column 1) = 2.2 and suspension velocity (column 2) $=3$ then actuator force (column 3 ) required is $\mathbf{- 5 9 1}$. 
This means that when suspension moves by $2.2 \mathrm{~cm}$ with velocity of $3 \mathrm{~m} / \mathrm{s}$ then the actuator must provide a force of $-591 \mathrm{~N}$ to keep the system stable. Figure 9 shows the representation of case 1 .

\section{Case-2}

When suspension travel (column 1) is $\mathbf{- 2}$ and suspension velocity (column 2) is $\mathbf{- 1 . 2}$ then required actuator force (column 3) is $\mathbf{4 2 2}$.

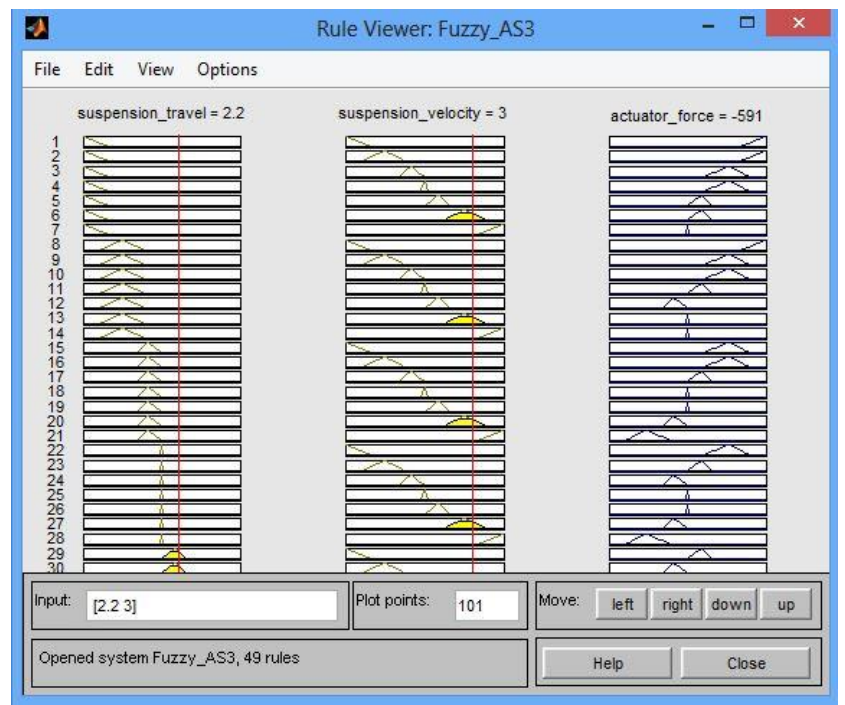

Figure 9. Case 1 representation in MATLAB

This means that when suspension moves by $-2 \mathrm{~cm}$ with velocity of $1.2 \mathrm{~m} / \mathrm{s}$ then the actuator must provide a force of $422 \mathrm{~N}$ to keep the system stable.

Figure 10 shows the representation of case 2.

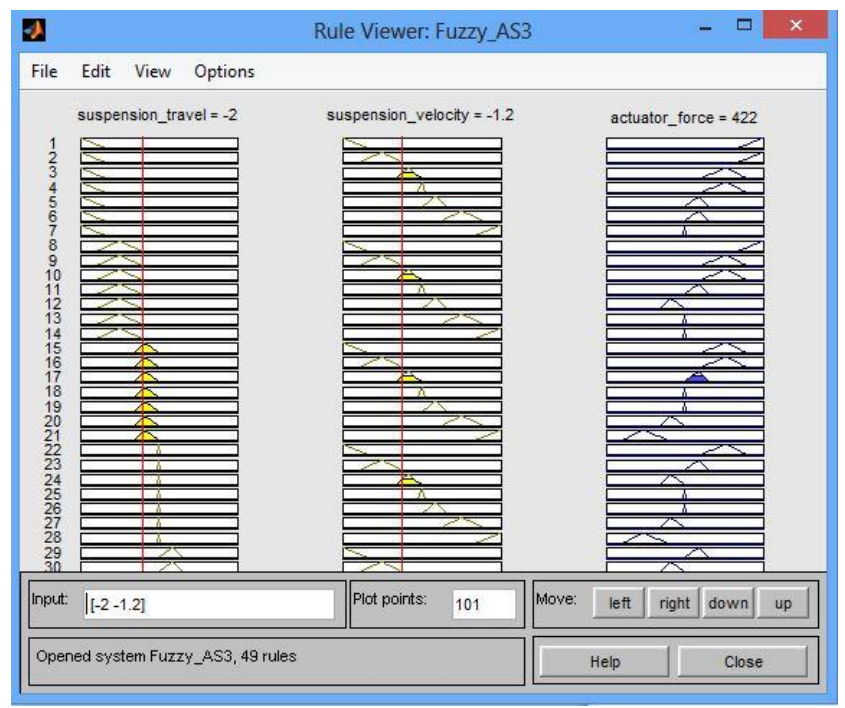

Figure 10. Case 2 representation in MATLAB

\section{E. SIMULINK Model}

The Simulink model represents the quarter car model of vehicle that simulates the active suspension system. The model represents a wheel with stiffness and damping and a shock absorber with stiffness and damping and a fuzzy controller for active control. In Simulink model the suspension displacement and suspension velocity given as inputs to the fuzzy controller and the output of fuzzy controller is given to Simulink model of suspension system. As shown in Figure 11, fuzzy logic controller output is given to mass of car and mass of wheel. As we know that suspension effect is depends on mass of car and wheel. For observation of damping effect, the second order integrator is used for mass of car and wheel. The whole set up is observed with the help of step input.

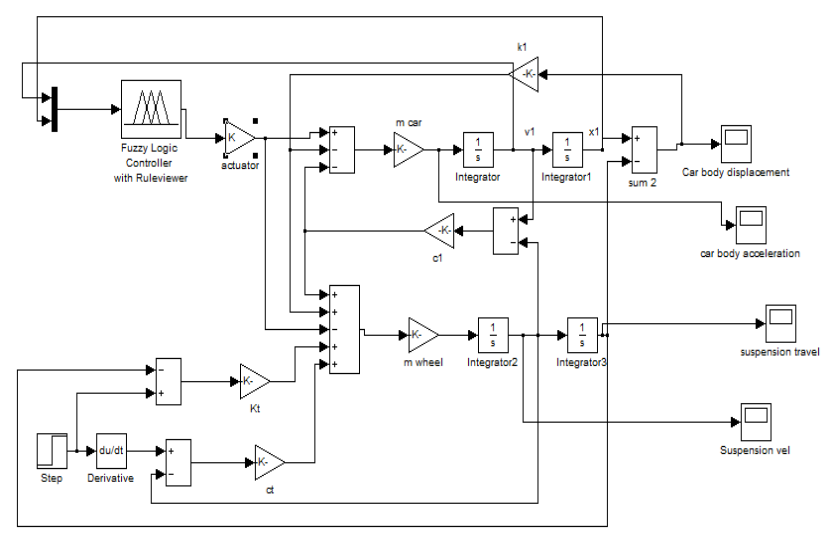

Figure 11. Simulink model of quarter car model for active suspension system

\section{1) Output of Simulink model}

The output of Simulink model was obtained by providing various bump height by varying the step input. In the output of Simulink model, the displacement for active and passive suspension systems are compared by obtaining the displacement vs time graph for same bump height. It can be seen from the graphs that the displacement is reduced in case of active suspension system compared to passive suspension system. It is also observed that the time required for obtaining the required damping in case of active suspension system is very less compared to passive suspension system. Figure 12 shows the displacement vs time graph of active suspension system for bump height of $0.1 \mathrm{~m}$, it can be seen from the graph that the displacement is $15 \mathrm{~mm}$ whereas in case of passive suspension system, it is $30 \mathrm{~mm}$ which is seen in figure 13 . Also, the time required for active suspension system is 0.65 sec while for passive suspension system it is $5.5 \mathrm{sec}$.

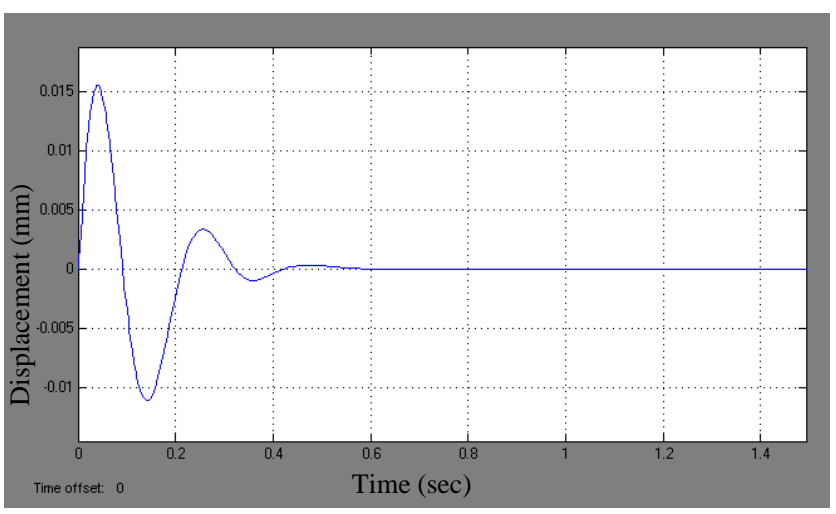

Figure 12. Displacement vs time graph for $0.1 \mathrm{~m}$ bump in Active suspension

Published By:

Blue Eyes Intelligence Engineering 


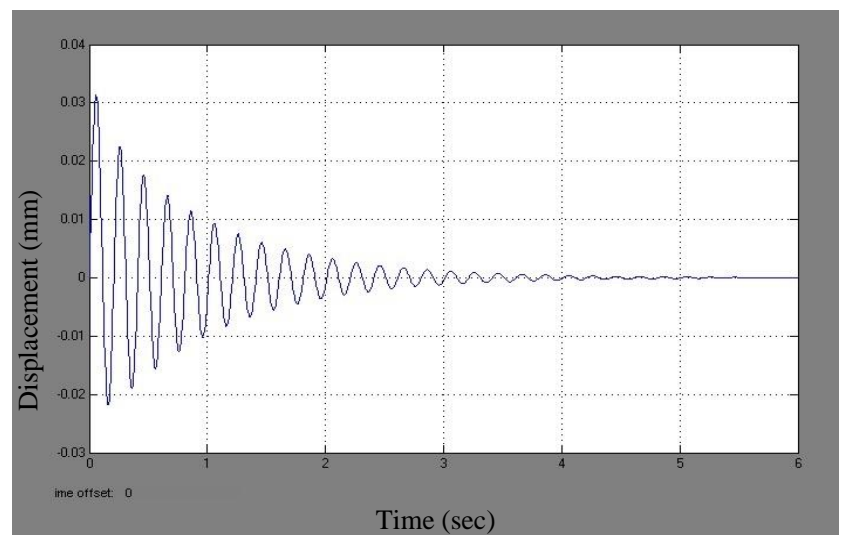

Figure 13. Displacement vs time graph for $0.1 \mathrm{~m}$ bump in Passive suspension

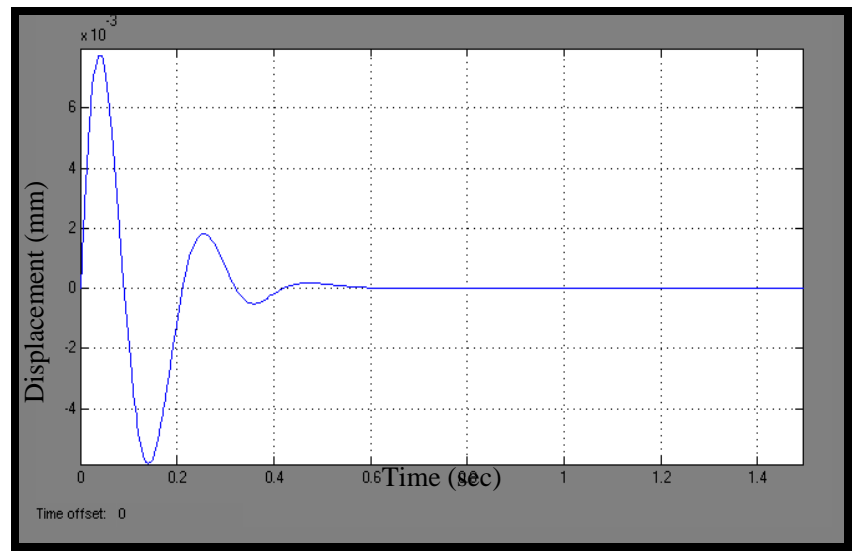

Figure 14. Displacement vs time graph for $0.05 \mathrm{~m}$ bump in Active suspension

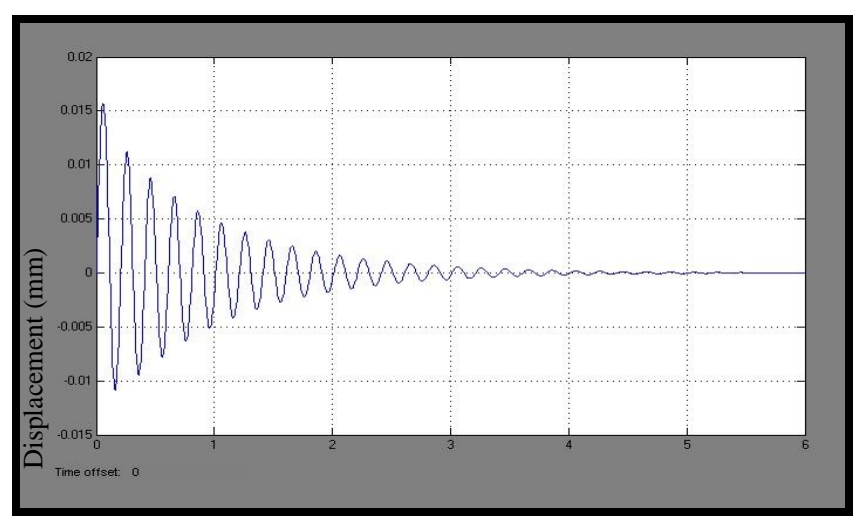

Figure 15. Displacement vs time graph for $0.05 \mathrm{~m}$ bump in Passive sumpensection

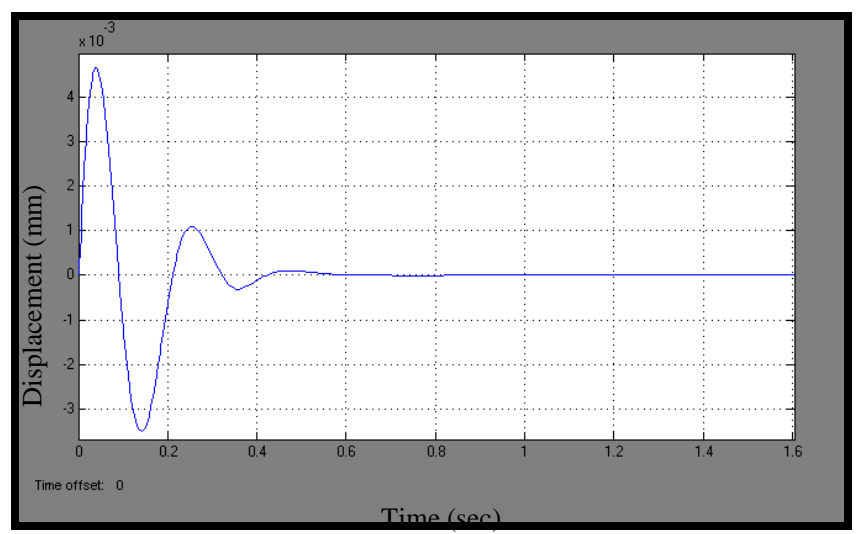

Figure 16. Displacement vs time graph for $0.03 \mathrm{~m}$ bump in Active suspension
Figure 14 shows the displacement vs time graph of active suspension system for bump height of $0.05 \mathrm{~m}$, it can be seen from the graph that the displacement is $7 \mathrm{~mm}$ whereas in case of passive suspension system, it is $15 \mathrm{~mm}$ which is seen in Figure 15. Also, the time required for active suspension system is $0.65 \mathrm{sec}$ while for passive suspension system it is $5.5 \mathrm{sec}$.

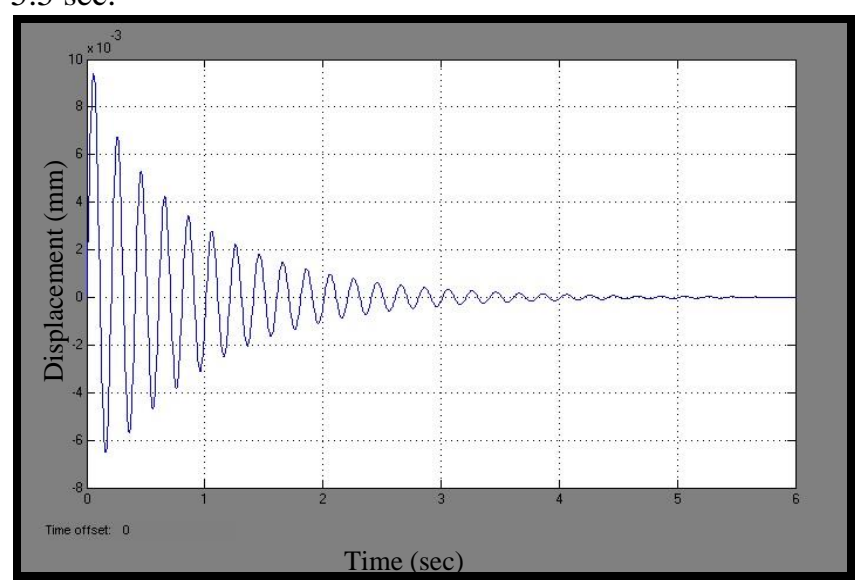

Figure 17. Displacement vs time graph for $0.03 \mathrm{~m}$ bump in Active suspension

Similarly, figure 16 shows the displacement vs time graph of active suspension system for bump height of $0.05 \mathrm{~m}$, it can be seen from the graph that the displacement is $5 \mathrm{~mm}$ whereas in case of passive suspension system, it is $10 \mathrm{~mm}$ which is seen in Figure 17. Also, the time required for active suspension system is $0.65 \mathrm{sec}$ while for passive suspension system it is $5.5 \mathrm{sec}$.

\section{2) Simulation Results}

Table 2. Simulation results

\begin{tabular}{|c|c|c|c|c|c|c|}
\hline $\begin{array}{c}\text { Sr. } \\
\text { No. }\end{array}$ & $\begin{array}{c}\text { Bump } \\
\text { Height } \\
(\mathrm{mm})\end{array}$ & \multicolumn{2}{|c|}{ Initial Displacement (mm) } & \multicolumn{2}{|c|}{ Settling time } \\
\hline & & Active & Passive & $\begin{array}{c}\text { \% } \\
\text { change }\end{array}$ & Active & Passive \\
\hline 1 & 100 & 15 & 30 & 50 & 0.65 & 5.5 \\
\hline 2 & 50 & 7 & 15 & 53 & 0.65 & 5.5 \\
\hline 3 & 30 & 5 & 10 & 50 & 0.65 & 5.5 \\
\hline
\end{tabular}

The Table 2 depicts the displacement in case of active system is decreased by $50 \%$ compared to the passive system. The Figures 12 to17 depict that the time required for active system is also reduced to a great extent.

\section{EXPERIMENTAL ANALYSIS}

\section{A. Experimental Setup}

Experimental setup is developed to validate the simulation work. Following figure 18 shows the experimental setup. Experimental setup consists of two rolling wheels, shock absorber, actuator, hydraulic power-pack and various sensors.

Published By:

Retrieval Number: C5994029320/2020@BEIESP

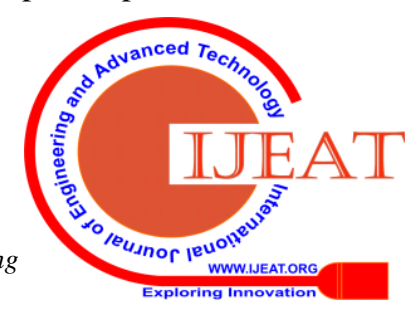


The lower wheel is considered as reference wheel for road surface. The upper wheel imitates the wheel of vehicle whereas lower wheel animates relative road motion. The upper wheel is driven by the lower wheel with friction contact and the lower wheel is driven by the 2 HP 1500rpm motor.

The tyre and shock absorber represents the passive suspension system. For converting it into active suspension system the actuator is placed parallel to the shock absorber. The actuator is controlled by 4/3 DC solenoid valve which is controlled electronically.

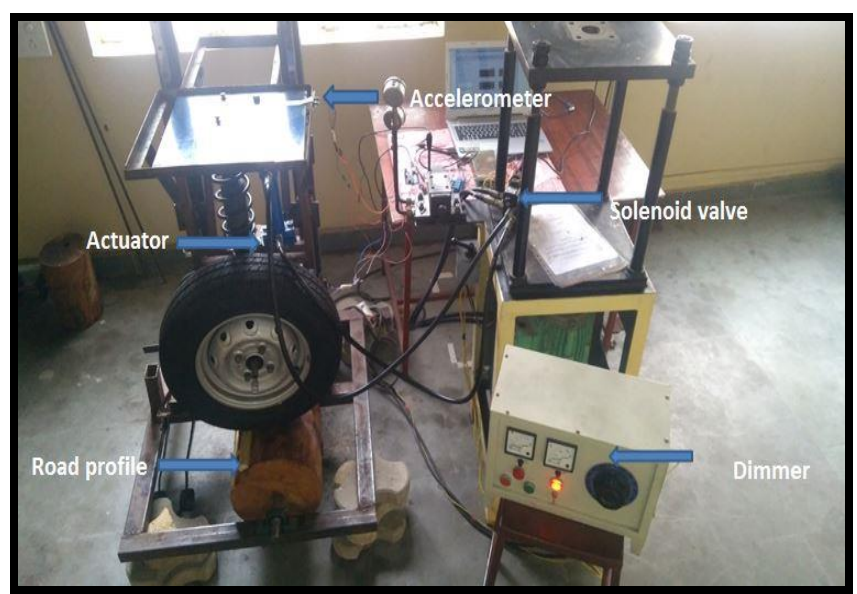

Figure 18. Experimental Setup

Experimental setup consists of following parts as shown in Table 3.

Table 3. Bill of material

\begin{tabular}{|c|l|c|}
\hline $\begin{array}{c}\text { SR } \\
\text { NO. }\end{array}$ & \multicolumn{1}{|c|}{ Name } & Quantity \\
\hline 1 & Alto wheel & 1 \\
\hline 2 & Wooden wheel & 1 \\
\hline 3 & Shock absorber & 1 \\
\hline 4 & DC Motor 2HP 1500rpm & 1 \\
\hline 5 & Linear guide ways (2 rails \& 4 blocks) & 1 \\
\hline 6 & Dimmer & 1 \\
\hline 7 & Hydraulic power pack & 1 \\
\hline 8 & Actuator & 1 \\
\hline 9 & Solenoid valve & 1 \\
\hline 10 & Manifold block & 2 \\
\hline 11 & ADXL 345 accelerometers & 2 \\
\hline 12 & Arduino & 2 \\
\hline
\end{tabular}

Wooden wheel is placed below alto wheel which gives us road condition to perform test. The motor speed is controlled with the help of dimmer stat. Motion of reference wheel is transferred to wheel which is connected to sprung mass with help of MacPherson strut and actuator. The two linear vertical guide ways are used for up and down sliding motion. Accelerometers are attached at the sprung mass and the unsprung mass for measuring the acceleration, velocity and displacement. The actuator is placed parallel to the shock absorber and connected to hydraulic power-pack with the help of solenoid valve. The direction of control and flow of actuator is controlled by solenoid valve. Hence the actuator provides required additional force to achieve stability of sprung mass. The experimental test conducted on the road surface is shown in Figure 19.

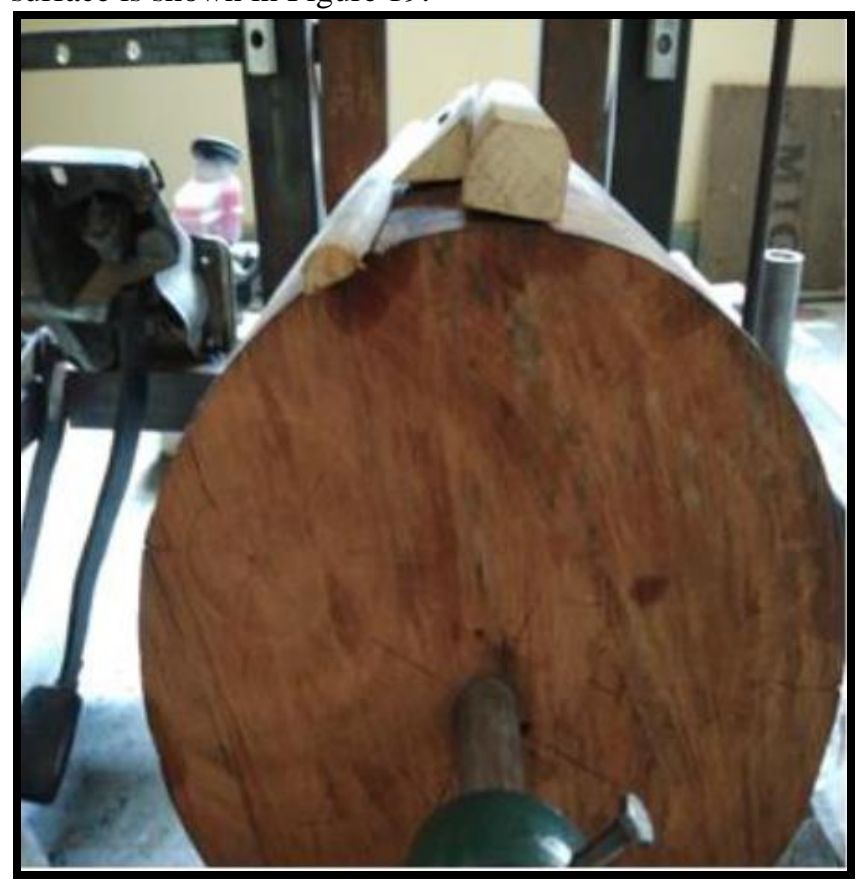

Figure 19. Rough road

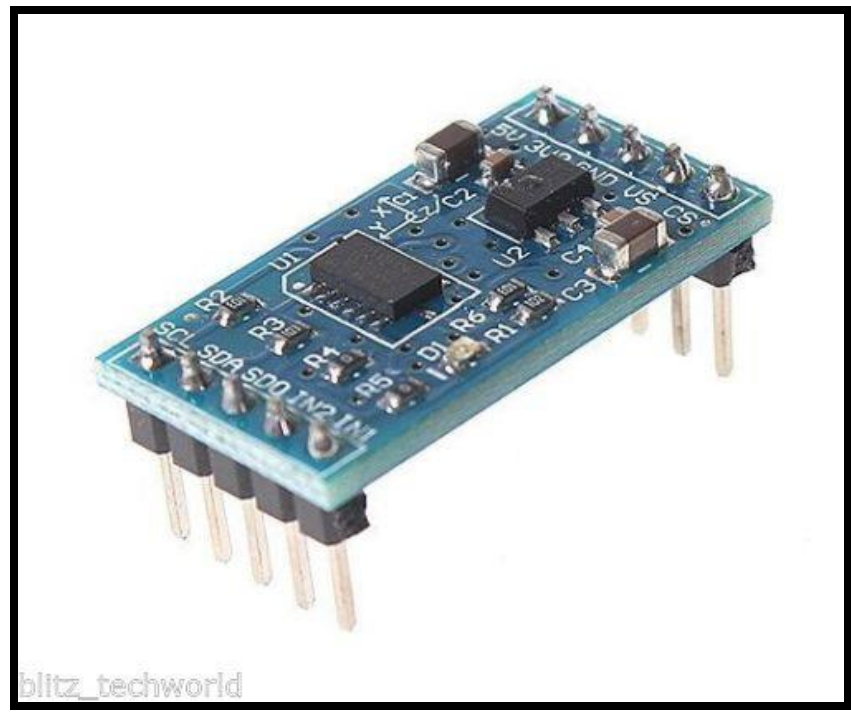

Figure 20. ADXL 345 accelerometer

The Figure 20 shows the accelerometer used for calculating the acceleration, velocity and displacement of the sprung and unsprung mass. 


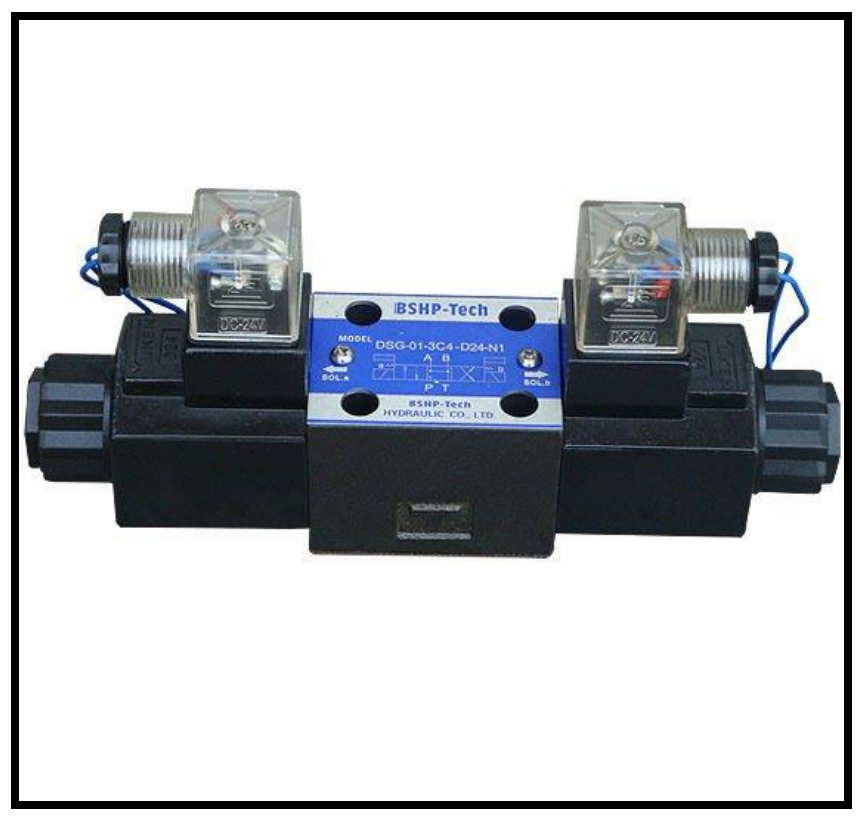

Figure 21. Solenoid valve

Figure 21 represents a 4 port 3-way direction control valve. This valve is used to control the direction and time of the actuator. This solenoid valve is controlled electronically by interfacing it by using Arduino with LabView software.

\section{B. Calculations of Hydraulic actuator}

The following calculations were done for calculation of force and response time of actuator

\section{1) Calculation for force:}

a) Area of cylinder during forward stroke

Diameter of cylinder $(\mathrm{D})=42 \mathrm{~mm}$

Area on piston head side $A_{f}=\frac{\pi}{4} D^{2}=\frac{\pi}{4} 42^{2}=1384.74 \mathrm{~mm}^{2}$

b) Area of cylinder during return stroke

Diameter of piston $(\mathrm{d})=32 \mathrm{~mm}$

Area on piston rod side $A_{r}=\frac{\pi}{4}\left(D^{2}-d^{2}\right)=$

$\frac{\pi}{4}\left(42^{2}-32^{2}\right)=580.9 \mathrm{~mm}^{2}$

c) Force applied by Actuator.

Pressure of oil $=2 \mathrm{~N} / \mathrm{mm}^{2}$

Pressure $=\frac{\text { force }}{\text { area }}=\frac{\mathrm{F}}{\mathrm{A}}$

Therefore Force $=$ Pressure $*$ Area of cylinder

$$
=2 * 1384.74=2769.48 \mathrm{~N}
$$

The above force calculation is done for the oil pressure of 2 $\mathrm{N} / \mathrm{mm}^{2}$, similarly calculations for various pressure ranges are also done.

\section{2) Response time of actuator}

Oil flow rate capacity of pump $(\mathrm{Q})=2.5 \mathrm{lpm}$

$1 \mathrm{lpm}=16666.67 \mathrm{~mm}^{3} / \mathrm{s}$

Therefore $2.5 \mathrm{lpm}=2.5 * 16666.67=41666.675 \mathrm{~mm}^{3} / \mathrm{s}$

a) Response time during forward stroke

Velocity $\left(\mathrm{V}_{\mathrm{f}}\right)=\frac{Q}{A_{f}}=\frac{41666.675}{1384.74}=30.08989 \mathrm{~mm} / \mathrm{s}$

Calculating the time for a stroke length of $10 \mathrm{~mm}$

Time for forward stroke $\left(\mathrm{T}_{\mathrm{f}}\right)=\frac{\text { Stroke }}{v_{f}}=\frac{10}{30.08989}=0.332 \mathrm{~s}$

b) Response time for return stroke

Velocity $\left(\mathrm{V}_{\mathrm{r}}\right)=\frac{Q}{A_{r}}=\frac{41666.675}{580.9}=71.727793 \mathrm{~mm} / \mathrm{s}$
Calculating the time for a stroke length of $10 \mathrm{~mm}$

Time for forward stroke $\left(\mathrm{T}_{\mathrm{r}}\right)=\frac{\text { Stroke }}{v_{r}}=\frac{10}{71.727793}=0.139 \mathrm{~s}$

The above response time calculations are done for the stroke length of $10 \mathrm{~mm}$, similar calculations are also done for stroke length varying from $1 \mathrm{~mm}$ to $100 \mathrm{~mm}$.

\section{LabVIEW Program}

LabVIEW program is used to provide an interface between the hardware and software. Here LabVIEW program is made to provide the inputs from accelerometer to the fuzzy controller and then providing the output of fuzzy controller to the solenoid valve. For this purpose, we connect the accelerometers to the Arduino Uno. The Arduino Uno is connected to the system containing LabVIEW. From the inputs of accelerometers, we calculate the acceleration, velocity and displacement. Out of this the velocity and displacement are provided as an input to the fuzzy controller. The output of the fuzzy controller is than again provided to the solenoid valve from the digital output channels of the Arduino Uno.

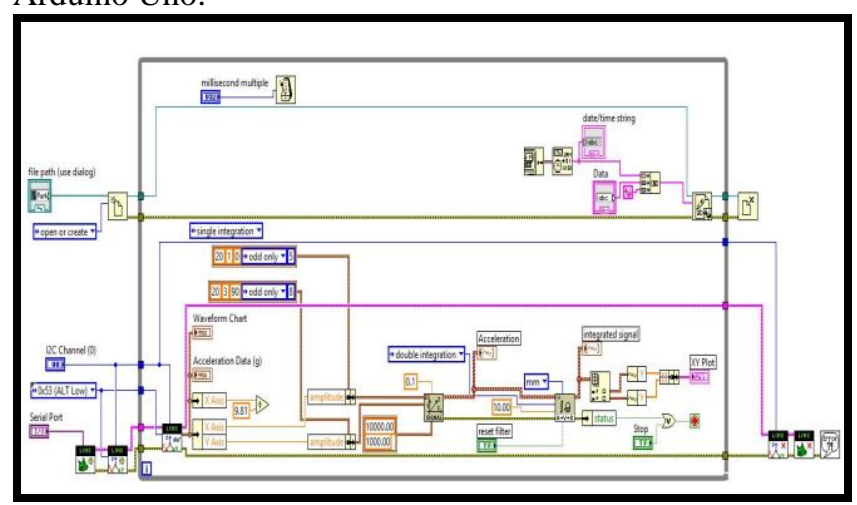

Figure 22. Block diagram for accelerometer

The fuzzy controller designed in MATLAB was developed in the same manner in LabVIEW. The detailed block diagrams of LabVIEW are explained in the Figures 22 and 23. Figure 22 represents the LabVIEW block diagram for interfacing ADXL 345 accelerometer whereas Figure 23 represents the block diagram with fuzzy control. Figure 24 represents front panel of LabVIEW program. On the left-hand side of fig there are configurations settings which contain two serial ports where we can provide address of Arduino. In the solenoid input channels block we provide the digital output pin numbers of Arduino which will provide the input to solenoid valve. On the left-hand bottom corner of the Figure we provide address of the fuzzy logic controller which is imported into the program. 


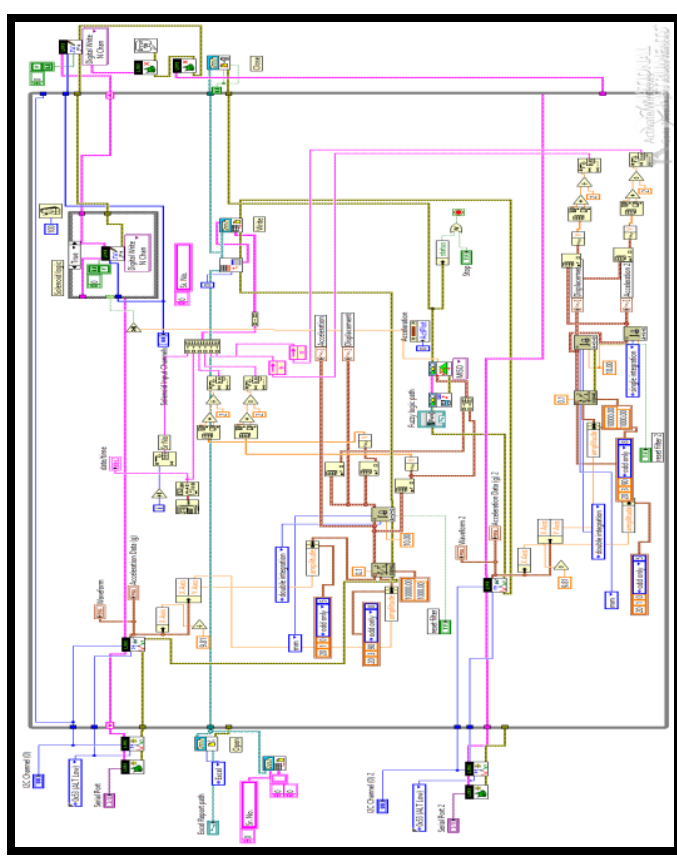

Figure 23. Block diagram with fuzzy control

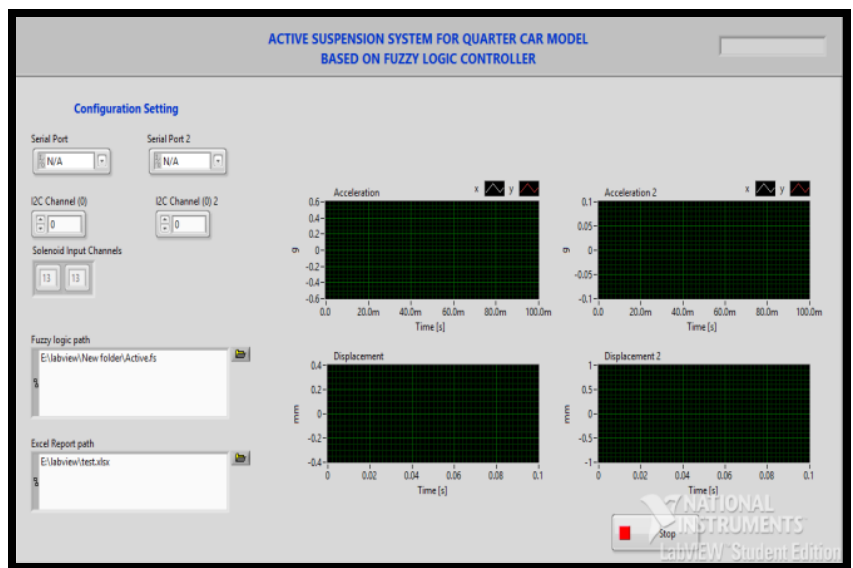

Figure 24. Front panel of Lab VIEW

Below that there is an excel report path where the output is saved in the excel sheet in tabular forms. On the right-hand side, there are graphs for acceleration and displacement for two accelerometers connected to system.

\section{Results}

Number of real time experiments has been performed and results are compared with simulation results. The experiments have been taken for $30 \mathrm{~mm}$ and $50 \mathrm{~mm}$ bump height at a speed of $10 \mathrm{~m} / \mathrm{s}$ i.e. $36 \mathrm{~km} / \mathrm{hr}$. It should be noted that on the available setup experiments can be performed for specific road condition i.e. for dry conditions only.

\section{1) Results for passive system}

\section{a) Bump height 50mm}

The displacement results of passive system recorded by the accelerometer for a bump of $50 \mathrm{~mm}$ is plotted in Figure 25.

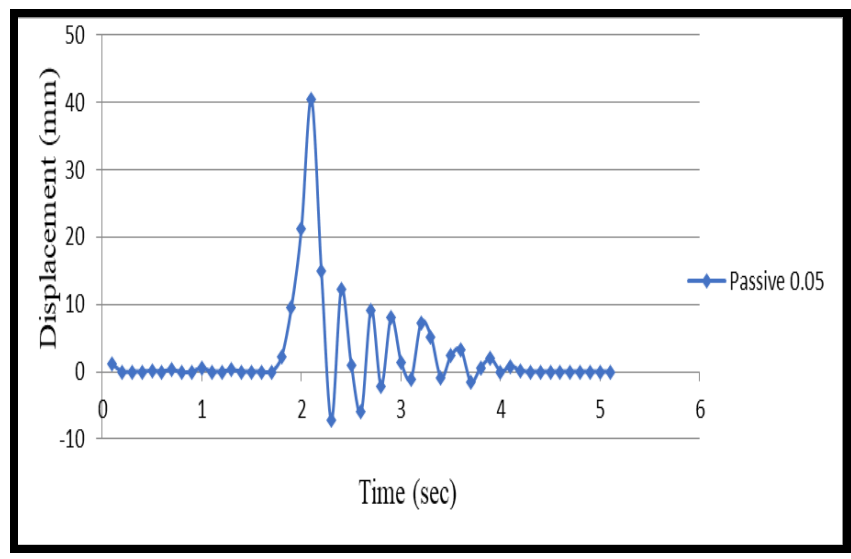

Figure 25. Displacement vs Time for passive system with bump of $50 \mathrm{~mm}$

From the Figure 25 it is seen that the peak value is $40 \mathrm{~mm}$, hence when a bump of $50 \mathrm{~mm}$ was provided the passive system reduced the displacement by $10 \mathrm{~mm}$. It can be observed from graph that for a bump of $50 \mathrm{~mm}$ the maximum displacement in passive system is $40 \mathrm{~mm}$ and the settling time is 2.5 seconds.

\section{b) Bump height $30 \mathrm{~mm}$}

The displacement results of passive system recorded by the accelerometer for a bump of 30mm is plotted in Figure.26.

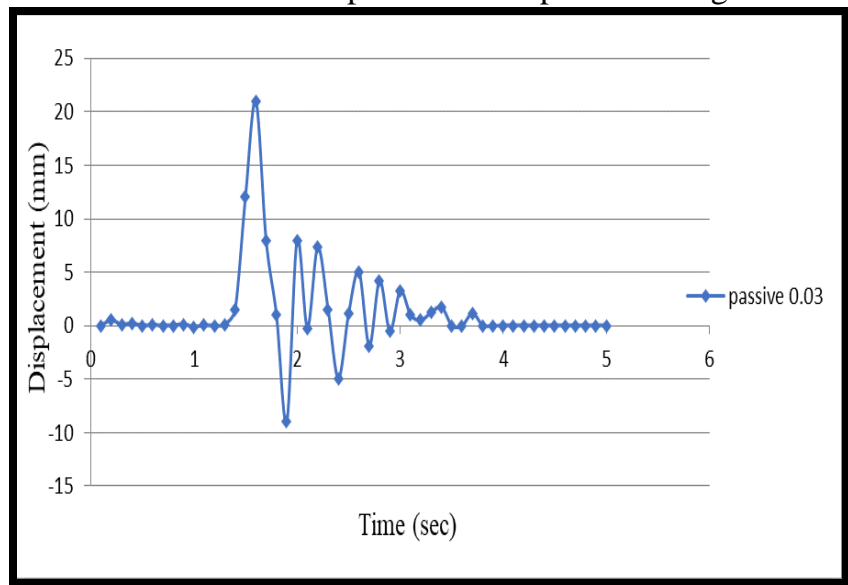

Figure 26. Displacement vs Time for passive system with bump of $30 \mathrm{~mm}$

From the Figure.26 it is seen that the peak value is $21 \mathrm{~mm}$, hence when a bump of $30 \mathrm{~mm}$ was provided the passive system reduced the displacement by $9 \mathrm{~mm}$. It can be observed from graph that for a bump of $30 \mathrm{~mm}$ the maximum displacement in passive system is $21 \mathrm{~mm}$ and the settling time is 2.5 seconds.

\section{2) Results for active system}

a) Bump height $50 \mathrm{~mm}$

The displacement results of active system recorded by the accelerometer for a bump of 50mm are plotted in Figure 27. From the Figure.27 it is seen that the peak value is $33 \mathrm{~mm}$, hence when a bump of 50mm was provided the active system reduced the displacement by $17 \mathrm{~mm}$. 


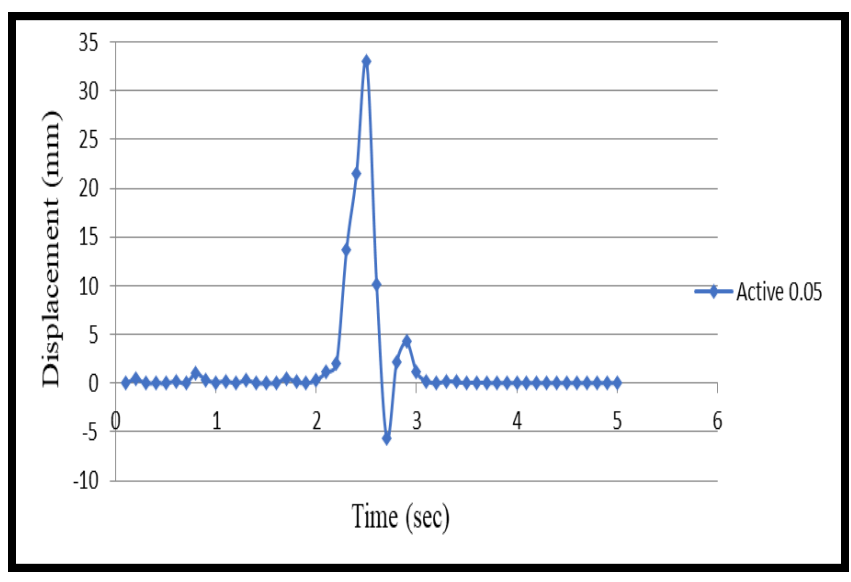

Figure 27 Displacement vs Time for active system with bump of $50 \mathrm{~mm}$

It can be observed from graph that for a bump of $50 \mathrm{~mm}$ the maximum displacement in passive system is $33 \mathrm{~mm}$ and the settling time is 1 seconds.

\section{b) Bump height $30 \mathrm{~mm}$}

The displacement results of active system recorded by the accelerometer for a bump of 30mm are plotted in Figure 28.

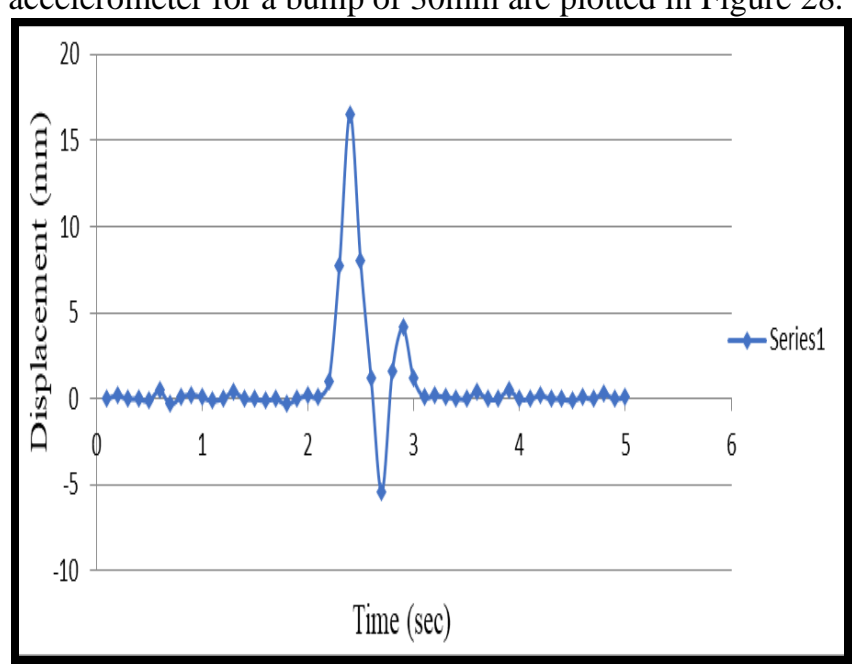

Figure 28. Displacement vs Time for active system with bump of $30 \mathrm{~mm}$

From the Figure 28 it is seen that the peak value is $16.52 \mathrm{~mm}$, hence when a bump of $30 \mathrm{~mm}$ was provided the active system reduced the displacement by $12.5 \mathrm{~mm}$. It can be observed from graph that for a bump of $30 \mathrm{~mm}$ the maximum displacement in passive system is $16.52 \mathrm{~mm}$ and the settling time is 1 seconds.

The Table 4 shows the tabulated experimental results for displacement and settling time.

Table 4. Experimental results

\begin{tabular}{|c|c|c|c|c|c|c|}
\hline $\begin{array}{c}\text { Sr. } \\
\text { No. }\end{array}$ & $\begin{array}{c}\text { Bump } \\
\text { Height } \\
(\mathrm{mm})\end{array}$ & \multicolumn{2}{|c|}{$\begin{array}{c}\text { Displacement (mm) } \\
\text { (First cycle) }\end{array}$} & \multicolumn{2}{|c|}{$\begin{array}{c}\text { Settling time } \\
\text { (sec) }\end{array}$} \\
\hline & & Active & Passive & $\begin{array}{c}\% \\
\text { change }\end{array}$ & Active & Passive \\
\hline
\end{tabular}

\begin{tabular}{|c|c|c|c|c|c|c|}
\hline $\mathbf{1}$ & 50 & 29 & 41 & 30 & 1 & 2.5 \\
\hline $\mathbf{2}$ & 30 & 15 & 21 & 29 & 1 & 2.5 \\
\hline
\end{tabular}

\section{3) Comparison of active and passive system}

Fig 29 shows the comparison of the graphs for a bump of $50 \mathrm{~mm}$ obtained from experimental results of active and passive suspension system. This graph clearly shows the difference in active and passive suspension system. The redline in graph indicates the passive system and blue indicates the active system. It can be observed that in active suspension system both the displacement and settling time is reduced.

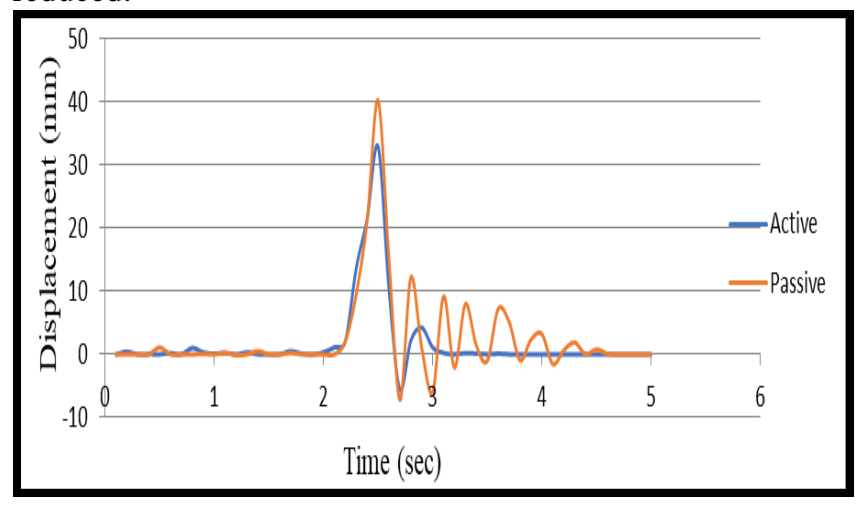

Figure 29. Comparison of active and passive suspension system for bump of $50 \mathrm{~mm}$

Figure 30 shows the comparison of the graphs for a bump of $30 \mathrm{~mm}$ obtained from experimental results of active and passive suspension system. This graph clearly shows the difference in active and passive suspension system. The red line in graph indicates the passive system and blue indicates the active system. It can be observed that in active suspension system the displacement and the settling time are both reduced.

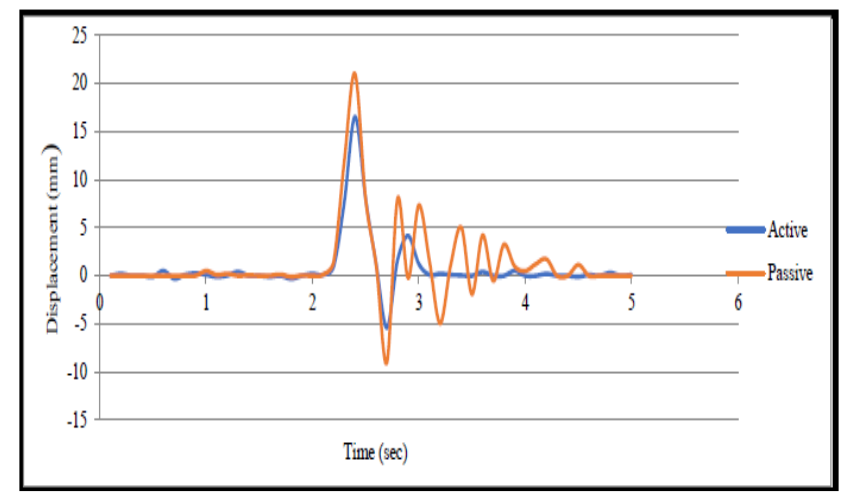

Figure 30. Comparison of active and passive suspension system for bump of $30 \mathrm{~mm}$

\section{RESULTS AND DISCUSSION}

Simulations basically involved in bringing mathematical or numerical model of your system into real world with the aid of computer software, while experimental analysis involves real life measurement.

Published By:

Blue Eyes Intelligence Engineering \& Sciences Publication 
The results are obtained by both simulation and experimental methods. A fuzzy logic controller is developed for active suspension system which provides the force as an output. For simulation the quarter car model was represented in the MATLAB Simulink model where the fuzzy controller was imported in the Simulink model and results for displacement were calculated for a bump of $100 \mathrm{~mm}, 50 \mathrm{~mm}$ and $30 \mathrm{~mm}$. The simulation results clearly show that the displacement in active system is decreased by $50 \%$. It is also seen that the settling time in case of active suspension system is decreased by $88 \%$.

A quarter car test rig is developed for obtaining experimental results. The hardware is interfaced with software (LabVIEW) by Arduino. The fuzzy controller is imported in the LabVIEW model and results are calculated for a bump of $50 \mathrm{~mm}$ and $30 \mathrm{~mm}$. The experimental results show that the displacement in active system is decreased by $29 \%$. It is also seen that the settling time in case of active suspension system is decreased by $68 \%$. The repeatability of experimental results was found to be $70 \%$.

\section{CONCLUSION}

For active suspension systems it is very much difficult to formulate a mathematical model and solve it theoretically up to the required accuracy. Hence this work is done by numerical methods. For gaining the active control in suspension systems we make use of actuators along with shock absorbers. Fuzzy controller takes the input of velocity and displacement of chassis and provides the actuator force as an output. This output is provided to the suspension system in the Simulink model and results are obtained. It is seen that a good amount of decrease is seen in the displacement of chassis.

In Experimental analysis, the decrease in displacement of chassis due to a bump is found for both active and passive suspension system. From the experimentation it is clear that reduction of chassis displacement is more in case of active suspension system compared to passive suspension system and the experimental and simulation results match approximately. Hence active suspension systems must be used.

\section{REFERENCES}

1. Wei Wang, Yuling Song, Yanbing Xue, Hongling Jin, Juncai Hou, Minglei Zhao, An optimal vibration control strategy for a vehicle's active suspension based on improved cultural algorithm, Applied Soft Computing 28 (2015) 167-174.

2. Weichao Sun, Huihui Pan, Yifu Zhang, Huijun Gao, Multi-objective control for uncertain nonlinear active suspension systems, Mechatronics 24 (2014) 318-327.

3. M. Soleymania, M. Montazeri-Gh, R. Amiryan, Adaptive fuzzy controller for vehicle active suspension system based on traffic conditions, Scientia Iranica B (2012) 19 (3), 443-453.

4. Wei-Yen Wanga,1, Ming-Chang Chenb, Shun-Feng Sub, Hierarchical T-S fuzzy-neural control of anti-lock braking system and active suspension in a vehicle, Automatica 48 (2012) 1698-1706.

5. Guido Koch, Enrico Pellegrini, Sebastian Spirk and Boris Lohmann, Design and Modeling of a Quarter-Vehicle Test Rig for Active Suspension Control, Technical Reports on Automatic Control Vol. TRAC-5, July 21, 2010.

6. Jeen Lin, Ruey-Jing Lian, Chung-Neng Huang, Wun-Tong Sie, Enhanced fuzzy sliding mode controller for active suspension systems, Mechatronics 19 (2009) 1178-1190.
7. Semiha Turkay, Hu seyin Akc, Aspects of achievable performance for quarter-car active suspensions, Journal of Sound and Vibration 311 (2008) 440-460.

8. T. Yoshimura, a. Kume, m. Kurimoto and j. Hino, Construction of an Active Suspension System of a Quarter Car Model Using the Concept of Sliding Mode Control, Journal of Sound and vibration (2001) 239(2), 187\}199.

9. Nizar Al-Hol, Jonathan Weave, Ph.D. and Dae Sung Joo, Adaptive Fuzzy Logic Based Controller for an Active Suspension System, University of Detroit Mercy.

10. P. Swethamarai, P. Lakshmi, Design and Implementation of Fuzzy-PID Controller for an Active Quarter Car Driver Model to minimize Driver Body Acceleration, IEEE International Systems Conference (SysCon) 2019, Orlando, FL, USA, 8-11 April 2019.

\section{AUTHORS PROFILE}

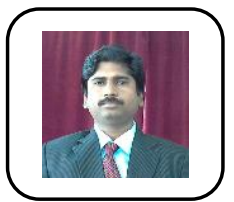

N.Vivekanandan, is currently working as the Assistant Professor in the department of Mechanical Engineering at Pimpri Chinchwad College of Engineering, Pune and is pursuing his Ph.D in Pune University. His area of interest includes Mechanical System Design, Vibration and Automotive safety. He completed his undergraduate degree in Mechanical Engineering in the year 1998 from Bharathiyar University, Coimbatore and, obtained his Post graduate degree in the year 2008 from National Institute of Technology (NIT), Trichy from the department of Mechanical Engineering with Industrial Safety Engineering as specialization. He is currently pursuing his Doctorate research in the area of Anti-lock Braking system (ABS). He has published papers in reputed National, International Conferences and Journals. He is a recipient of G.E. Foundation Scholar- Leader Program scholarship.

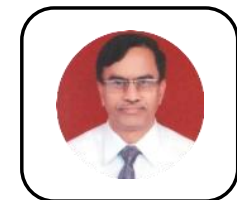

Dr.A.M.Fulambarkar, is currently working as Principal, Pimpri Chinchwad College of Engineering, Pune. He carries academic and administrative experience of more than 30 years. He has been awarded Ph.D. in Mechanical Engineering by Nagpur University, Nagpur. He has published and presented research papers in various national and international conferences. He was chairman, Board of Studies of Mechanical Engineering in Nagpur University from 2000 to 2005 . He is a Rotarian and associated with many Social Organizations. 